\title{
Study of Systems Methodology in ERP Implementation in China
}

\author{
Li Zhang ${ }^{1}$, Shuojia Guo ${ }^{2}$, Yanping Liu', and Jung Choi ${ }^{3}$ \\ 1 School of Economics and Management, Beijing Jiaotong University, \\ Beijing 100044, China. \\ 1zhang@center.njtu.edu.cn \\ WWW home page: http://jingguan.njtu.edu.cn \\ 2 School of Management, Huazhong University of Science and \\ Technology, Wuhan 430074, China \\ 3 Department of Information Systems and Operations Management \\ Wright State University \\ Dayton, OH 45435,USA
}

\begin{abstract}
The application and evolution of MRP II/ERP can be roughly divided into three stages: the introduction stage, the growth stage, and the maturity stage in Chinese enterprise. A successful ERP implementation requires knowledge on both ERP systems and business management. In implementing ERP, the business processes of those enterprises adopted ERP systems need to be examined. It is important to understand the ERP system itself and the business processes involved with the ERP systems and the enterprises adopted ERP systems. In order to resolve issues that may appear in the process of implementing ERP system, this paper proposes that a systematic analysis of those significant factors involved with implementing ERP systems is a necessity, especially if such analysis is conducted in the framework of systems science.
\end{abstract}

\section{Introduction}

With the global economy and the wide application of information technology and ecommerce, we are striding towards the era of knowledge economy from industrial economy era. In this transition, fundamental changes have been taken place in the business environment ( $\mathrm{Li}, 2000 \mathrm{a}$ ). For example, customers' demands change fast; the pace of technological innovations accelerates; products life cycle is shortening; and the market is becoming more and more competitive (Xu et al., 2005). Among those changes, there are three major factors that are influencing a modern enterprise's

Please use the following format when citing this chapter.

Zhang, L., Guo, S., Liu, Y., Choi, J., 2006, in International Federation for Information Processing, Volume 205, Rescarch and Practical Issues of Enterprise Information Systems, eds. Tjoa, A.M., Xu, L., Chaudhry, S., (Boston:Springer), pp.655-666. 
growth and survival. They are customer, competition and change. The business management good in the era of the industrial economy including the management style relying mainly on MRP II is no longer applicable in today's enterprises. In order to adapt to the external environment and taking customer, competition and change into consideration, enterprises must manage the change in business operations, reengineer business process, and adopt managerial reforms.

This paper analyzes some problems appear in implementing ERP using the data on ERP implementation in China, and discussing ERP implementation, implementation procedures, key successful factors, and the risk factors in the framework of systems theory and systems approach.

\section{ERP Implementation in Chinese Enterprise}

MRP/MRPII/ERP systems have been introduced into China and adopted for almost 20 years (Li, 2000b; Li et al., 2001; Chaudhry et al., 2005; Dan et al., 2005; Wang et al., 2005). In early 1980s, most Chinese enterprises have limited knowledge on MRP II and ERP. During the period of 1985 to 1990 , Chinese entrepreneurs and researchers began to study western business management and practice to help improve the competitiveness of Chinese enterprises. At the same period, selected enterprises started to adopt ERP systems. From 1990 to 1999, an increasing number of enterprises have adopted ERP systems in which most of them are the leading products from major ERP vendors in the West. The introduction and application of MRP II/ERP systems in China can be roughly divided into three stages:

\subsection{Introduction Stage}

This stage nearly runs through the whole 1980s which is characterized by the introduction and implementation of MRP II. Such applications are mainly in traditional machine-building industry. 1980s was the period when China started the transition towards market economy. Production and operation was a serious issue needs to be handled since the productivity per worker in Chinese machine-building industry was approximately only one tenth of that developed countries. Cycle of delivering products was long, inventory was high, cash flow was not good, and the utilization rate of equipments was low. For the purpose of improving performance, some enterprises started adopting MRP II systems. Such companies include the Shenyang Air Blower Plant, and Guangzhou Peugeot Motor Corporation.

As pioneers in adopting MRP II systems in China, these companies experienced a lot of difficulties. First, the software itself had technical problems. The software introduced at the time was non-general purpose systems mostly developed for mainframes or middle-range systems. Such software needed customization that could be costly. Another problem was the lack of related technical support and service. Second, there was a shortage of the expertise of implementing MRP II. Another obstacle is that sufficient attention was not been paid by management on systems 
implementation. MRP II implementation was perceived as an IT project only. Despite the difficulties, some enterprises successfully implemented the systems. Such companies include Beijing First Machine Tool Plant, Shenyang Machine Tool Plant, and Shenyang Air Blower Plant.

As a result, some practitioners considered that imported MRP II software does not meet the Chinese industry needs. After analyzing the MRP II implementation results in this period, the so-called "three $1 / 3$ " rule was proposed, i.e., $1 / 3$ of imported MRP II software can be used, $1 / 3$ can be used only after modification, and another $1 / 3$ simply cannot be used.

\subsection{Growth Stage}

This stage was roughly from 1990 to 1996 in which the so-called "three $1 / 3$ " rule was no longer popular. During this period, MRP II and ERP systems were widely adopted and implemented.

During this stage, the imported software still played a major role. However, the faster transition from the old planning economy to market economy and the changes in world market gave a serious challenge to the traditional management style in Chinese companies. Although MRP II still was the main software to be used for modernizing the manufacturing sector, its applications spread quickly to industry sectors other than machine-building that include space industry, electronics, pharmaceutical and chemical industry. Companies in this list include Chengdu Aircraft Industry Company and the First Automobile Factory of China--Volkswagen Automobile Group. In addition, companies that adopted MRP II earlier have benefited significantly from the installed systems after participating in China's 863 CIMS Program. For example, Beijing First Machine Tool Plant realized the integration between the core production management and all other functional units that can be used to adjust production planning according to the rapid change of the market. As a result, the efficiency was up for more than 30 times. The companies in this category have all financially benefited from implementing MRP II systems.

However, it cannot be ignored that, although significant achievements have been made, there are still a great deal of weaknesses. Some of which are: (1) many enterprises were lack of planning for choosing and using MRP II; (2) application scope was not wide enough. Most existing applications confined to the manufacturing sector; (3) the scope and function of management were limited to enterprises' internal operations rather than integrating all partners in the supply chain; (4) some enterprises did not thoroughly look into the function of the software and the technical support from vendors after acquiring it, which caused unnecessary waste.

\subsection{Maturity Stage}

It is the whole period from 1997 to the beginning of this century. The main characteristic is the introduction of ERP systems. The scope of application has been 
expanded from the manufacturing industry to other industry sectors. Meanwhile, the implementation result has also been improved significantly.

The rapid development of the third industry is considered a remarkable symbol of modern economic development. Financial management has already become the core of modern economy, as the information industry plays a leading role in modern economy. All of these are demanding a new type of management software. As a result, ERP becomes a major player and has expanded its application to financial sector, communication industry, high technology industry, and retail sector. For example, SAP has developed a product which can provide solutions for a variety of industry sectors including financial sector, high technology industry, transportation, telecommunications, energy, government, commerce and retail business, international trading, publishing, consulting service, even health care and hotel industry.

Existing problems include many enterprises fail to pursue business process reengineering along with the implementation of ERP which have caused the functions of ERP difficult to work well, domestic ERP market is not mature yet, regulations are needed for vendors, etc.

\section{Implementing ERP Systems in Systems Perspectives}

\subsection{Define ERP systems}

\subsubsection{Characteristics}

A successful implementation of ERP system requires both the knowledge on software and business processes. ERP is an enterprise information system that is consisted of business process management and information technologies, with the purpose of integrating and optimizing enterprise operations ( $\mathrm{Li}$ and $\mathrm{Li}, 2000)$. It has the following characteristics (Xu, 2000; Deng, 2003):

System characteristics: ERP is a system with characteristics of a system such as wholeness, holistic properties, structure, boundary, and functions. Its most important characteristic is holistic properties (Jackson 2003; Warfield 1989; Xu 1991; Xu 1995).

Business process management: The core of ERP is managerial thinking and business process management including supply chain management, total quality control, flexible manufacturing systems, and activity business cost method, etc.

Information technology: ERP will not exist without information technology. It can be seen clearly that it is the technological advances in information technology that makes ERP possible. On the other hand, information technology is also benefited from the development of ERP systems. ERP can be considered as a system that integrates all functional units in an enterprise including marketing, production, material management, financial accounting, and human resource with the help of information technology. 


\subsubsection{ERP system architecture}

In June 2003, the Ministry of Information Industry of China released the national industry standard entitled "Enterprise Informationization Technological Regulation: Part 1: ERP Regulation "which was put into practice in October 2003 (Chinese Ministry of Information Industry, 2003). In this document, the section on "ERP products functional requirements" provides the requirements for ERP architecture, which include: Function Classifications, Environment and User Interface, System Integration, System Management, Basic Information, Inventory, Purchasing, Marketing, BOM, Work in Progress, Techniques, MRP, Cost, Human Resource, Quality Management, Managerial Decision, General Ledger, Automatic Entries, Receivable, Payable, Fixed Assets.

These facto show the required functions of ERP including the requirement for the entire system, management function, basic information management function, production management function, supply management function, marketing management function, human resource management function, financial management function, material management function, technology management function, quality management function, and management decision function. Each of them relates to a corresponding subsystem of ERP. An enterprise determines the functions needed and defines its own ERP scope, subsystems, and boundary.

\subsection{Systems management thinking embedded in ERP systems}

For a successful implementation of ERP systems, it is important to have an adequate understanding of the systems management thinking embedded in ERP systems which can be summarized as follows:

Systems view. ERP systems are characterized by the concept of systems planning (Warfield, 1989; 1990) that includes planning from macro level down to micro level, from strategic level down to tactical level, and from general to specific. However, such planning is consistently focusing on an enterprise's strategic target. "One system plan" is the spirit of ERP.

Systems management. ERP is an example of systems engineering; it integrates every division in an enterprise into a whole. Each division needs to try its best to fulfill its own responsibility in the framework of the system as a whole, and every employee should be clear about his/her role. Only under the "One system plan", ERP can become and function as a system. The situation of functional separation needs to be replaced by the team spirit with systems perspectives.

System-wide data sharing. ERP is an enterprise information system in which each division of the enterprise practicing management using the same data. Any changes in data can be accessed by all divisions to realize true data sharing. Managing and making decisions based upon a central database can eliminate the problems such as insufficient information, and decisions made on unclear fuzzy data. Therefore, adequate attention should be paid to data quality. 
Dynamic systems reaction to changes. ERP systems integrate customers' demands and the manufacturing activity inside the enterprise with suppliers, realizing the idea of complete service to customers. Meanwhile, ERP can trace, monitor, and reflect the operation status of the enterprise to make it more adaptable to the market and customers' demands. It is extremely important that management can quickly react to the changing data and make decisions. Therefore, enterprise information consciousness should be emphasized.

Systems forecasting. ERP systems not only reflect the status of enterprise management, but also can help solve "what-if" problems. It can be used to predict the problem that may appear in the future so as to take measures in advance instead of wasting time and energy in handling them after they have already occurred.

Systematic integration of material flow and money flow. ERP itself has the function of cost management and financial accounting. It can produce financial reports directly from the activity in production. To convert material flow into money flow directly may guarantee the consistency of production and the financial data. Financial department can obtain the money flow information which reflects the material flow and the condition of production on time, and be able to analyze the financial performance of the enterprise and participate in decision making at any time.

\subsection{The concept of level in ERP implementation}

To understand the levels involved with ERP in terms of systems theory is the key to put ERP into practice successfully. The levels of ERP can be mainly decomposed into the level of system architecture and the level of system integration.

\subsubsection{Levels in systems architecture}

The structure of ERP is composed of four levels: (1) Network level. It is the infrastructure of the system which makes the information flow both internal and external enterprise flows smoothly through the network; (2) Resources level. It includes hardware, software, and data needed by ERP system; (3) Application level. It contains different subsystems used by the personnel in different sections in an enterprise. Through these subsystems, management provides ERP with the data resource or obtains the required information; (4) Decision support level. Employing models and methods, management processes data or information for decision making.

\subsubsection{Levels involved with system implementation and integration}

Based on the integration nature of ERP, there are three levels involved. They are the levels of management thinking, software, and management system (see Fig. 1). 


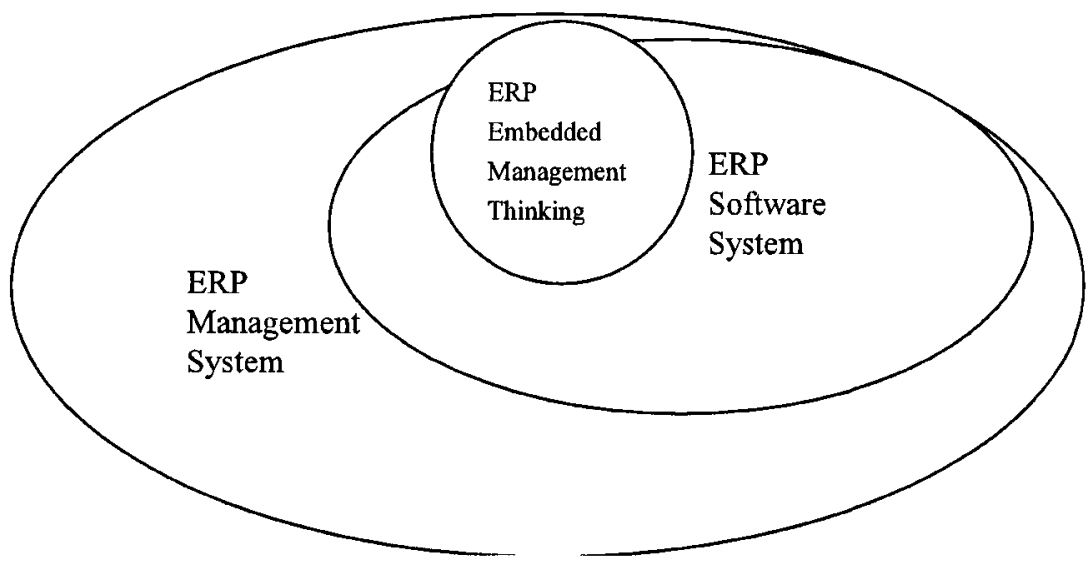

Fig. 1. Levels in ERP Integration

The substance of managerial thinking embedded in ERP is based upon MRP II and supply chain management ideas. The software level covers client server system, database, object-oriented technology, graphical interface, and network architectures, etc., and serving the purpose of supply chain management. The management system level makes ERP possible to be a truly enterprise information system that integrates enterprise management principles, business process, enterprise business data, resources, and computer systems into a single system. Through the three levels mentioned above, enterprises will be directly benefited from the management system that is also the system actually make the other two levels realized. A failure in any links in the interaction process of these three levels is a risk factor that may lower the benefits which the management system could bring to the enterprise. Therefore, the main issue to be paid attention when an ERP system is evaluated is the quality of the software and the effect of implementation which actually covers all three levels mentioned above.

\subsection{ERP implementation techniques}

\subsubsection{Conversion methods}

The methods of conversion can be roughly classified as follows. (1) Complete conversion method: With this method, the entire ERP system is implemented in full scale at once; all modules of the system are put into operation at the same time; (2) Progressive conversion method: subsystems or modules are implemented one at a time. Implementation schedule may go by units within an enterprise; (3) Wave-type conversion method: the course of ERP system implementation is advanced by wavetype of movement. Each such wave provides appropriate system functions to different units within the enterprise. Although each wave is an independent entity, they are also related to each other to some extent. It is managed by the project team 
to ensure the success of the entire implementation; (4) Special type progressive conversion method. This method recommends a temporary linkage between the new system and the existing system. With this method, more than one module may be implemented at the same time; (5) Parallel conversion method. The new and existing systems may be operated at the same time for a certain period of time. The purpose is to guarantee that new ERP system will reach expected performance.

\subsubsection{Relationship between implementation method and enterprise characteristics}

Selecting an appropriate ERP implementation method is mainly depend upon the internal characteristics within an enterprise. The factors to be considered include:

(1) Organization scale and complexity

Generally, it is suitable for a small and less complex organization to take the method of complete conversion. A relatively complex organization may adopt the progressive conversion method. With the increase of scale and complexity, an enterprise may incline to adopt the progressive conversion method (see Fig. 2).

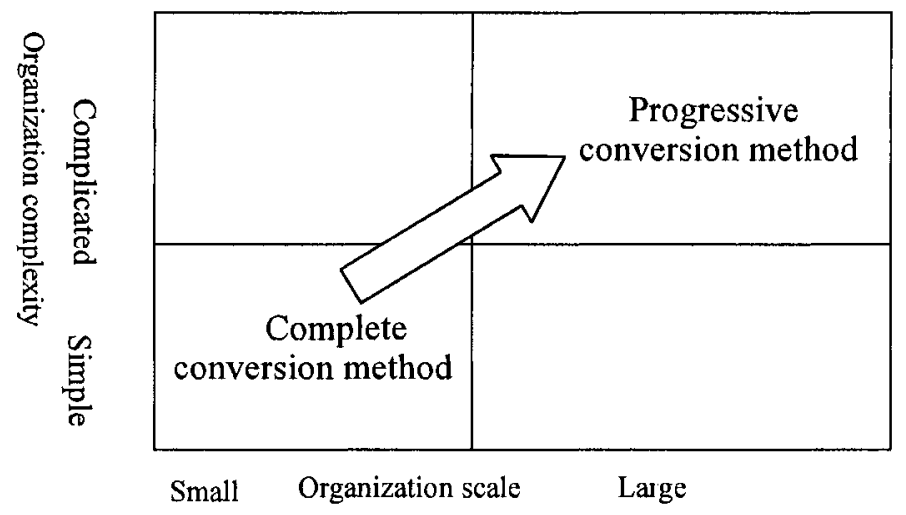

Fig. 2. Relationship between the scale and complexity of organization and the methods of system implementation (Peng, 2001; Yuan 2002)

\section{(2) Levels of organization and degree of control}

Factors such as levels of the organization and the degree of control should also be considered in selecting an implementation method. A single-level enterprise with loose control management style may adopt the complete conversion method. A multi-level organization with tight control management style may take progressive conversion method (see Fig. 3). 


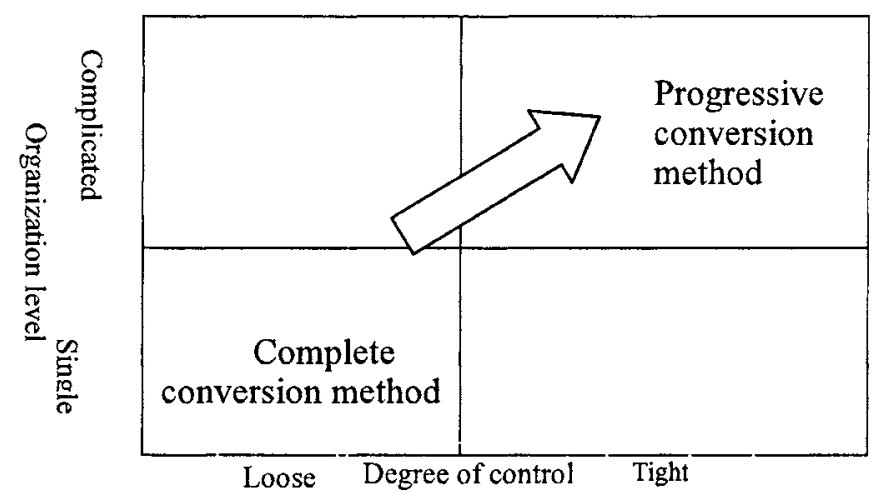

Fig. 3. Relationship between the levels of the organization and the degree of control and the methods of system implementation

\section{(3) Scope of implementation}

The scope of implementation also influences the choice of implementation method. The scope is generally defined by the quantity of modules and the extent of customization which is shown in Fig. 4 (Guan 2002).

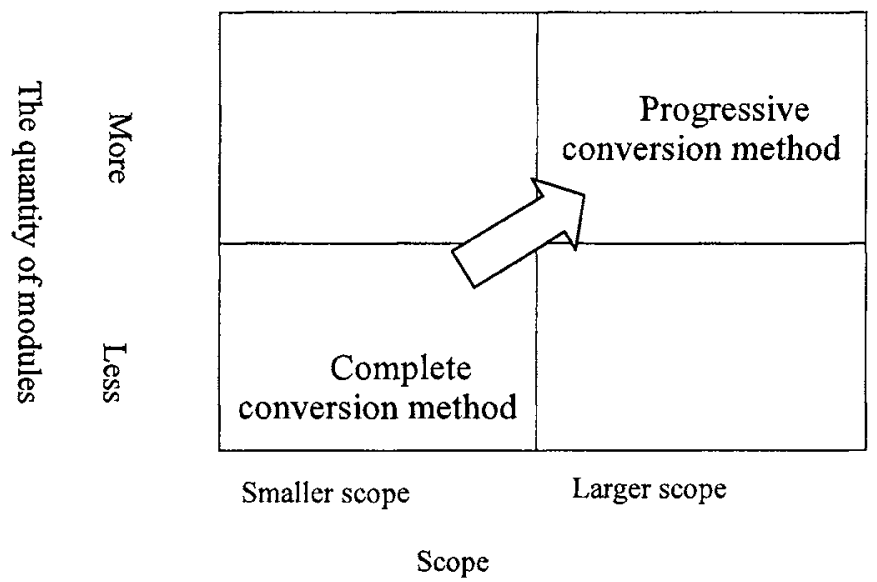

Fig. 4. Relationship between the system modules and the methods of system implementation

\subsection{Key successful factors of ERP implementation for Chinese Enterprises}

Based on the empirical studies of ERP implementation in Chinese enterprises, the key successful factors of implementing ERP system are as follows: 
(1) Senior level management support: positive commitment, enthusiastic about the project and strong support; (2) project implementation team: Teams' organization and project implementation, for example, qualified management and team members. Team members must have background and are capable. For example, they must have experiences and be able to communicate in a cross-departmental environment; (3) external consultants: knowledge and expertise on ERP project; (4) setting goals and project scope: goals and project scope for each stage must be determined; (5) education and training: basic education of ERP and ERP system operation training; (6) project management: according to the project goal, determining project plan, allocating resources, and controlling cost and budget; (7) data: data accuracy and integrity; (8) change management: BPR; (9) methods of implementation; (10) evaluation: ERP project evaluation and assessing the contribution made by ERP to enterprise performance.

\section{Conclusions}

Implementing ERP systems is a deep revolution in management. In order to achieve the goal, issues in the implementation process must be systematically considered. This study attempts to propose a systems approach to ERP implementation through a systematic analysis of the factors involve in the implementation process, thus to provide solutions to a variety of problems arise in the course of implementing ERP and reduce risks.

The study proposes the definition of ERP in systems point of views. ERP is an integrated enterprise information system composed of managerial thinking and information technology. Its main purpose is to integrate and optimize an enterprise's resources. The managerial consideration of ERP includes: (1) feasibility and consistency of the plan; (2) systems characteristics of management; (3) data sharing: ERP makes it possible for different sections/divisions of an enterprise to operate using the same database. Any changes in data can be reflected on a real-time basis; (4) dynamic reaction to changes; (5) what-if-analysis; (6) the integration of material flow and money flow; and (7) the comprehensiveness of the management scope.

The study also proposes the concept of levels in ERP system. Due to the integration nature of ERP systems, three main levels can be defined. They are the levels of management thinking, software, and management system. Based upon the analysis of ERP implementation, it is proposed that only in the direction of systems approach or scientific approach can the ERP project be successfully carried out. A typical ERP implementation process mainly includes pre-preparation stage, implementation preparation stage, test operation and customization stage, and new system operation stage. There are control points at each stage which include those key control points which are critical to the success of the implementation. In addition, the paper also discusses the risk factors and how to avoid them. 
ERP implementation itself is a project of system engineering or practice of systems science. A through analysis of the systems characteristics and factors is considered a necessity as basis for the successful implementation of ERP systems.

\section{References}

1. J.C. Ang, Sum, and K. Yang, MRP II Company Profile and Implementation Problems: A Singapore Experience, International Journal of Production Economics 34(1), 35-45 (1994).

2. P. Bingi, M. Sharma, and J. Godia, Critical Issues Affecting an ERP Implementation, Information Systems Management 16(3), 7-14 (1999)

3. S. Chaudhry, S. Feng, H. Li, L. Li, H. Sui, J. Zhang, Z. Zhang, and L. Xu, Production Research in China, International Journal of Production Research 43(12), 2355-2358 (2005).

4. Chinese Ministry of Information Industry. National Industry Standard: Enterprise Informationization Technological Regulation: Part 1: ERP Regulation, Beijing, (2003).

5. B. Dan, L. Li, X. Zhang, F. Guo, and J. Zhou, Network-Integrated Manufacturing Systems, International Journal of Production Research 43(12), 2631-2647 (2005).

6. C. Deng, A Directory of the ERP Application (Electronics Industry Press, Beijing, 2003).

7. C. Holland and B. Light, A Critical Success Factors Model for ERP Implementation, IEEE Software, 16(3), 30-36 (1999).

8. Z. Guan, Research on the Theory and Methods of Enterprises' Informationization, Doctoral Thesis, Beijing Jiaotong University, Beijing (2002).

9. M. Jackson, Systems Thinking: Creative Holism for Managers (Wiley, New York, 2003).

10. L. Li, Manufacturing Capability Development in a Changing Business Environment, Industrial Management and Data Systems 100(5-6), 261-270 (2000a).

11. L. Li, An Analysis of the Sources of Competitiveness and Performance of Chinese Manufacturers, International Journal of Operations and Production Management 20(3), 299315 (2000b).

12. L. Li, S. Chaudhry, P. Chaudhry, and Y. Wang, An Evaluation of Acquiring and Implementing A Manufacturing Resource Planning System, Production and Inventory Management Journal 42(3-4), 1-8 (2001).

13. $\mathrm{H}$. $\mathrm{Li}$ and $\mathrm{L}$. Li, Integrating Systems Concepts into Manufacturing Information Systems, Systems Research and Behavior Science 17, 135-147 (2000).

14. H. Miser, Handbook of Systems Analysis (Elsevier Science, 1985)

15. A. Parr, G. Shanks, and P. Darke, Identification of Necessary Factors for Successful Implementation of ERP Systems. New Information Technologies in Organizational Processes: Field Studies and Theoretical Reflections on the Future of Work. IFIP TC8 WG8.2 International Working Conference, p 99-119. (1999).

16. Z. Peng, Research on the Increment Courses of Value Chain based on IT Manufacturing Industry, Doctoral Thesis, Beijing Jiaotong University, Beijing. (2001).

17. A. Qayum, Social Cost-Benefit Analysis (HaPi Press, 1978).

18. C. Wang, L. Xu, X. Liu, and X. Qin, ERP Research, Development and Implementation in China: An Overview, International Journal of Production Research 43(18), 3915-3932 (2005). 
19. J.N. Warfield, Societal Systems (Intersystems Publications, Salinas, CA. 1989).

20. J.N. Warfield, A Science of Generic Design (Intersystems Publications, Salinas, CA. 1990).

21. L. Xu, Systems Characteristics in Information System Design, Systems Research 9(1), 6778 (1991). 